\title{
LA INFLUENCIA DE LOS LIBROS DE CABALLERÍAS EN LAS OBRAS CERVANTINAS SOBRE EL CAUTIVERIO
}

La búsqueda de fuentes literarias de las obras de Cervantes es un asunto de especial complejidad ${ }^{1}$, por la espesa trama de lecturas que se descubre en ellas, por la costumbre de este autor de reelaborar temas y reescribir asuntos de su propia producción y por la forma como todo esto se mezcla con sus recuerdos y experiencias ${ }^{2}$. Esto es especialmente visible en aquellas de sus obras en las que aparece el tema del cautiverio, en las que se descubren constantemente ecos de los cinco años que este autor pasó en Argel. No es de extrañar, por tanto, que al final de Los baños de Argel, uno de los personajes señale el carácter histórico de esa obra:

No de la imaginación

este trato se sacó,

que la verdad lo fraguó

bien lejos de la ficción.

Dura en Argel este cuento

de amor y dulce memoria, y es bien que verdad e historia alegre al entendimiento ${ }^{3}$.

1 Este trabajo se inscribe en el marco del Proyecto I+D+i del MINECO DHuMAR Humanidades Digitales, Edad Media y Renacimiento. 1. Poesía 2. Traducción (FFI2013-44286-P).

2 Jean Canavaggio, Cervantes, entre vida y creación, CEC, Alcalá, 2000 y Antonio Rey Hazas, Miguel de Cervantes. Literatura y vida, Alianza, Madrid, 2005.

3 Los baños de Argel, en Miguel de Cervantes, Obras completas, ed. Florencia Sevilla Arroyo, Castalia, Madrid, 1999, p. 972a. Todas las citas de esta obra en el presente estudio proceden de esta edición. 
Cervantes, que había conocido la dura realidad del cautiverio, quiso dramatizarla y ofrecerla al espectador, alguno de los cuales quizá también reconocería en esos episodios vivencias propias. La realidad de algunos nombres y hechos históricos, la forma como se describen los intentos de huida y la crueldad de algunos castigos están atestiguados por otras fuentes y confirman que efectivamente la comedia parte de las experiencias del autor en Argel.

No obstante, como es frecuente en la obra de Cervantes, la experiencia vital y la tradición literaria se mezclan de forma no siempre fácil de separar ${ }^{4}$. El tema del cautiverio presenta en muchas ocasiones reminiscencias literarias evidentes. Rey Hazas, en su estudio sobre las comedias cervantinas sobre el cautiverio, ya señaló que "la relación entre vida y literatura se instala decisivamente en el eje de todo análisis que quiera dar cuenta del tema del cautiverio en la obra cervantina"s. Este tema fue asumido por la literatura de la época y destacó sobre todo en la comedia. Canavaggio -siguiendo algunas conclusiones de Ruffinato, Meregalli o Fothergill-Payne ${ }^{6}$ - ha indicado cómo se desarrolló entre finales del siglo Xvi y principios del siglo XVII la comedia de cautivos, con los conocidos ejemplos de Cervantes y de Lope de $\mathrm{Vega}^{7}$, entre los que se estableció un

4 "En las obras cervantinas, el frecuente tema del cautiverio, tratado en tonos muy diversos, se inspira a veces en las propias experiencias del autor, aunque casi siempre resulta difícil o imposible deslindarlas claramente de los elementos inventados, de pura fantasía, por el modo característico de Cervantes de subordinar lo autobiográfico o histórico al arte, de utilizarlo en función primordialmente poética" (STANislav Zimic, Las novelas ejemplares de Cervantes, Siglo Veintiuno de España, Madrid, 1996, p. 45).

5 Antonio Rey Hazas, "Las comedias de cautivos de Cervantes", en Los imperios orientales en el teatro del Siglo de Oro. Actas de las XVI Jornadas de teatro clásico, eds. Felipe B. Pedraza Jiménez y Rafael González Cañal, Universidad de Castilla La Mancha, Almagro (Ciudad Real), 1994, p. 29.

${ }^{6}$ Aldo Ruffinato, Funzione e variabili in una catena teatrale: Cervantes $e$ Lope de Vega, Giapicchelli, Torino, 1971; Franco Meregalli, "De Los tratos de Argel a Los baños de Argel", en Homenaje a Casalduero, Gredos, Madrid, 1972; Louise Fothergill-Payne, "Los tratos de Argel, Los cautivos de Argely Los baños de Argel: tres «trasuntos» de un asunto", en El mundo del teatro en su Siglo de Oro: ensayos dedicados a John E. Varey, ed. J.M. Ruano de la Haza, Dovehouse, Ottawa, 1989, pp. 177-184; Jean CanavagGio, op. cit., p. 111.

${ }^{7}$ No entro aquí en los problemas de la atribución a Lope de Vega de la comedia Los cautivos de Argel, defendida por Ruth H. KossofT ("Los cautivos de Argel, comedia auténtica de Lope de Vega”, Homenaje a William L. Fichter, Castalia, Madrid, 1971, pp. 387-397) y rechazada por Angelo A. Portuondo 
interesante juego de referencias intertextuales no desprovistas de tintes paródicos.

El tema del cautiverio, por tanto, no era sólo un eco de una realidad de la época, sino una tradición literaria ${ }^{8}$. En dicha tradición, según determinó Camamis, había dos tipos de cautiverio: uno apoyado en la realidad histórica y otro en los modelos literarios de la novela griega y bizantina. Por su parte, la obra cervantina tiene tanto de uno como de otro tipo ${ }^{9}$.

Pero, además de los modelos de la literatura griega y latina citados por Camamis, existieron otros antecedentes sobre este tema, entre los que los libros de caballerías ocupan un lugar quizá más importante del que se ha querido ver.

En este sentido, destaca especialmente Palmerín de Olivia, uno de los más tempranos textos caballerescos renacentistas y el primer libro de caballerías que, siguiendo la estela amadisiana, presentaba personajes ajenos a este ciclo. Se convirtió así en la obra inicial de una de las series caballerescas más importantes y supuso una desviación clara del paradigma. Es indiscutible que Cervantes conocía bien este ciclo caballeresco, a juzgar por las menciones que hace en varias partes del Quijote, si bien resulta evidente la preferencia por otro de los títulos del ciclo, Palmerín de Inglaterra ${ }^{10}$; la buena imagen que se propone de éste

(Diez comedias atribuidas a Lope de Vega: estudio de la autenticidad, Biblioteca del Siglo de Oro, Charlottesville, 1980, pp. 41-62).

${ }^{8}$ Un interesante estudio de conjunto sobre esta realidad histórica es el de Maximiliano Barrio Gonzalo, "El corso y el cautiverio en tiempos de Cervantes", Investigaciones Históricas. Época moderna y contemporánea, Valladolid, 26 (2006), 81-114. Sobre el reflejo literario del cautiverio, véase Lisa VoigT, Writing captivity in the early modern Atlantic. Circulations of knowledge and authority in the Iberian and English imperial worlds, The University of North Carolina Press, Chapel Hill, 2009 y Ana María Rodríguez-Rodríguez, Letras liberadas: cautiverio, escritura y subjetividad en el Mediterráneo de la época imperial española, Visor/Libros, Madrid, 2013.

${ }^{9}$ George Camamis explica que "Cervantes, en cambio, se resiste, como en todo, a cualquier intento de encasillamiento fácil" (Estudios sobre el cautiverio en el Siglo de Oro, Gredos, Madrid, 1977, p. 14).

10 'Y, abriendo otro libro, vio que era Palmerín de Oliva, y junto a él estaba otro que se llamaba Palmerín de Ingalaterra; lo cual visto por el licenciado, dijo: -Esa oliva se haga luego rajas y se queme, que aun no queden della las cenizas; y esa palma de Ingalaterra se guarde y se conserve como a cosa única, y se haga para ello otra caja como la que halló Alejandro en los despojos de Darío, que la diputó para guardar en ella las obras del poeta Homero. Este libro, señor compadre, tiene autoridad por dos cosas: la una, porque él por sí es muy bueno, y la otra, porque es fama que le compuso un discreto rey 
(tanto del libro como de su protagonista) parece superar a la de su antecesor, Palmerín de Olivia, pero sus críticas a esta obra en el donoso escrutinio demuestran que conocía bien la obra fundacional de este ciclo, uno de los que gozaron de mayor éxito en el siglo XVI ${ }^{11}$.

Esta obra salió de las prensas salmantinas de Juan de Porras en 1511, pero fue reeditada en numerosísimas ocasiones; de hecho, fue el libro de caballerías más reeditado después de $A m a-$ dís de Gaula ${ }^{12}$. Fue elogiado por Juan de Valdés en su Diálogo de la lengua, al considerarlo por encima de otros textos caballerescos

a los quatro libros de Amadís, como a los de Palmerín y Primaleón, que por cierto respeto an ganado crédito conmigo, terné y juzgaré siempre por mejores que essotros Esplandián, Florisando, Lisuarte, Cavallero de la Cruz y que (a) los otros no menos mentirosos que éstos... ${ }^{13}$.

de Portugal. Todas las aventuras del castillo de Miraguarda son bonísimas y de grande artificio; las razones, cortesanas y claras, que guardan y miran el decoro del que habla con mucha propriedad y entendimiento. Digo, pues, salvo vuestro buen parecer, señor maese Nicolás, que éste y Amadís de Gaula queden libres del fuego, y todos los demás, sin hacer más cala y cata, perezcan" (DQI, cap. 6, p. 163b).

${ }^{11}$ Como personaje, en el Quijote sólo se cita a Palmerín de Inglaterra y no al de Olivia: "Tuvo muchas veces competencia con el cura de su lugar-que era hombre docto, graduado en Sigüenza-, sobre cuál había sido mejor caballero: Palmerín de Ingalaterra o Amadís de Gaula; mas maese Nicolás, barbero del mesmo pueblo, decía que ninguno llegaba al Caballero del Febo, y que si alguno se le podía comparar, era don Galaor, hermano de Amadís de Gaula, porque tenía muy acomodada condición para todo; que no era caballero melindroso, ni tan llorón como su hermano, y que en lo de la valentía no le iba en zaga" ( $D Q$ I, cap. 1, p. 153b); "Si no, díganme: ¿quién más honesto y más valiente que el famoso Amadís de Gaula?; ¿quién más discreto que Palmerín de Inglaterra?; ¿quién más acomodado y manual que Tirante el Blanco?; ¿quién más galán que Lisuarte de Grecia?; ¿quién más acuchillado ni acuchillador que don Belianís?; ¿quién más intrépido que Perión de Gaula, o quién más acometedor de peligros que Felixmarte de Hircania, o quién más sincero que Esplandián?; ¿quién más arrojado que don Cirongilio de Tracia?" (DQ II, cap. 1, p. 328a).

12 José Manuel Lucía Megías, "Libros de caballerías castellanos: textos y contextos", Edad de Oro, 21 (2002), 9-60 (para las ediciones de Amadís de Gaula, p. 47, para las de Palmerín de Olivia, p. 56). El estudio fundamental sobre el género caballeresco y su difusión impresa es también de este autor, Imprenta y libros de caballerías, Ollero \& Ramos, Madrid, 2001.

13 Juan de Valdés, Diálogo de la lengua, ed., introd. y notas de José F. Montesinos, Espasa-Calpe, Madrid, 1976, p. 173. La cita continúa con los otros libros que sitúa por debajo de los citados, a los que critica abiertamente: 
En el siglo XviI fue adaptado al teatro por Juan Pérez de Montalbán, como ha estudiado Claudia Demattè, que asimismo ha editado esta comedia ${ }^{14}$. El éxito de la obra traspasó nuestras fronteras, pues se tradujo a numerosas lenguas, en las que incluso motivó continuaciones oriundas de esos países. Por si fuera poco, se compusieron romances en torno a este libro, alguno de ellos ya en el siglo XviII ${ }^{15}$, lo que revela que esta obra $-\mathrm{y}$, en general, el género caballeresco- no cayó en el olvido tras la publicación del Quijote, como tantas veces se afirma, ya que precisamente es el éxito de lo caballeresco el que aseguraba el de su parodia cervantina, que tiene más de libro de caballerías de lo que se suele reconocer.

Pues bien, la influencia de la literatura caballeresca en general y de Palmerín de Olivia en particular en la configuración del tema del cautiverio es mayor de lo que pueda pensarse, y merece un estudio más detallado del que puedo ofrecer aquí y del que Albert Mas, en su amplio estudio sobre el tema turco, dedicó a los libros de caballerías, apenas una decena de páginas en su

"Guarino mezquino, La linda Melosina, Reinaldos de Montalván con La Trapesonda y Oliveros que es intitulado de Castilla, los quales, demás de ser mentirosíssimos, son tan mal compuestos assí por dezir las mentiras muy desvergonçadas, como por tener estilo muy desbaratado, que no hay buen estómago que los pueda leer" (pp. 173-174). Eso sí, reconoce haberlos leído todos y, aunque se arrepiente por considerar haber perdido el tiempo, confiesa haber pasado "diez años" en esas lecturas. Resulta significativo que sitúe los tres libros citados, en cuanto al estilo, por encima de otros, incluso por encima de las crónicas, y lo más que dice de la Crónica de Juan II es que "se puede leer para lo que pertenece a la lengua después de Amadís de Gaula, Palmerín y Primaleón" (p. 180). Esa buena consideración de Palmerín de Olivia, como es sabido, no parece ser compartida por Cervantes, a juzgar por el comentario sobre ella en el donoso escrutinio de la biblioteca de don Quijote, donde se ordena que se haga "rajas" como si fuera una aceituna (u oliva). Pero quizá esa crítica se deba a razones no enteramente literarias, como comentaré más adelante.

14 Juan Pérez de Montalbán, Palmerín de Olivia, ed. crítica, introd. y notas de Claudia Demattè, Mauro Baroni Editore, Pisa, 2006. Véanse también los comentarios de Claudia Demattè y Alberto del Río, Parodia de la materia caballeresca y teatro áureo. Edición de "Las aventuras de Grecia" y su modelo serio, el "Don Florisel de Niquea" de Montalbán, Universidad de Navarra, Pamplona, 2012.

${ }^{15}$ M. Carmen Marín Pina, "Romancero y libros de caballerías más allá de la Edad Media", en Actas del VI Congreso de la Asociación Hispánica de Literatura Medieval. Alcalá de Henares, 1995, ed. José Manuel Lucía Megías, Universidad, Alcalá de Henares, 1997, t. 2, pp. 977-987. 
monografía de dos volúmenes, en los que menciona sólo cinco títulos ${ }^{16}$.

El estudio de Mas cumplía sus objetivos panorámicos y, por ello, hay que resaltar que no olvidó los episodios de cautiverio que se narran en Palmerín de Olivia, que resume brevemente, si bien, como él mismo confiesa, no acudió al texto castellano, sino a la traducción francesa realizada por Jean Maugin impresa en París en $1553^{17}$. Aunque este investigador consideró que en este libro se encuentran las líneas maestras del tema turco, poco después matiza esta idea al afirmar que en esta obra se trata de un simple recurso para ampliar la geografía de las aventuras de sus protagonistas y que en la continuación de la obra se vuelve al tema de una forma menos relacionada con la realidad histórica ${ }^{18}$. No obstante, el tema del turco y del cautiverio presenta en Palmerín de Olivia unos matices bien distintos, empezando por la forma en la que el protagonista acepta ser hecho cautivo para salvar la vida y cómo actúa casi como esos renegados, pues, aunque no abandona su fe, es cierto que no duda en ayudar a los moros en sus ataques contra los cristianos ${ }^{19}$. Este asunto lo desarrollaré más adelante.

Por otra parte, quizá el hecho de haber utilizado la traducción francesa en lugar del texto original de Palmerín de Olivia explique por qué Mas indica que ese episodio apenas ocupa tres capítulos $^{20}$. Bien al contrario, en este libro son numerosas las

16 Albert Mas, Les turcs dans la littérature espagnole du Siècle d'Or (Recherches sur l'évolution d'un thème littéraire), Centre de Recherches Hispaniques-Institut d'Études Hispaniques, Paris, 1967, 2 ts. Mas comenta el tema turco en los libros de caballerías en las pp. 48-57 de su estudio, aunque, como he indicado, sólo habla de cinco títulos caballerescos: Amadís de Gaula, Sergas de Esplandián, Lisuarte de Grecia, Palmerín de Olivia y Palmerín de Inglaterra.

17 Mas, op. cit., n. 19, p. 54. Se trata, como él indica, del ejemplar Rés. Y2-140 de la Bibliothèque Nationale de Paris.

18 En relación con el Palmerín de Olivia afirma: "Si nous faisons abstraction des enchantements, sortilèges et aventures fantastiques, nous voyons se dessiner les grandes lignes des futures turqueries: voyage par mer, attaque des corsaires, captivité, amour entre maîtres et esclaves, enfin retour à la liberté" (MAs, op. cit., p. 55); "Turcs et chrétiens mènent la même sarabande que dans Las sergas de Esplandián ou dans Lisuarte de Grecia, sans raport direct avec la réalité du moment" $(i d$.$) .$

19 José Julio Martín Romero, "Palmerín de Olivia como enmienda del modelo amadisiano: el rechazo de la perfección arquetípica”, RLit, 76 (2014), núm. 152, 425-445.

20 "L'épisode est rapide; il comprend en tout trois chapitres" (Mas, op. cit., p. 55). 
páginas dedicadas a narrar el cautiverio de varios personajes, incluso el del protagonista. Como indicó Mancini, en la segunda parte de esta obra predomina el elemento turco ${ }^{21}$. De hecho, durante buena parte de la obra muchos personajes, incluyendo al protagonista, viven como cautivos ${ }^{22}$.

Efectivamente, en el capítulo LXIV se narra cómo unas naves turcas atacan a la de los héroes, que en su travesía habían decidido descansar tras una tormenta en una isla. Mientras el héroe decide salir a cazar, para distraerse, los demás personajes son asaltados de improviso y apresados en una escena típica del tema del cautiverio:

No tardó mucho, como Palmerín se fue por la montaña, que no vinieron cinco o seys naos de turcos que andavan de armada e havían corrido ansimesmo tormenta. E como fueron en aquel lugar e vieron la nao en que Trineo e Agriola estavan, cercáronla luego e como estava sobre áncora e no vieron quien la defendiesse, dieron salto en ella (p. 158) ${ }^{23}$.

Se nos cuenta que el capitán, llamado Olimael, seguía las órdenes del Gran Turco, "que lo avía embiado con toda aquella gente a tomar todas las naos de cristianos que fallase" (p. 160). Entre los cautivos se encuentra un amigo del héroe, Trineo, y su amada, Agriola, de cuyo papel durante el cautiverio hablaré más adelante. Su destino es amargo, pues son separados al no tener el mismo dueño.

A lo largo del libro se narran las razias de Olimael, que se dedicará a atacar tierras cristianas y a apresar numerosos cautivos para satisfacer a su señor; entre los lugares que atacan están la ciudad de Duraço -donde cautivan a la hija del duque del lugar, Laurena- y una villa del reino de Tesalia, a cuyo monarca, "fuele la ventura tan esquiva que la villa fue tomada de los moros"; tras todo lo cual "eran los cautivos tantos que no cabían

${ }^{21}$ Guido Mancini, Studi sul "Palmerín de Olivia". Introduzione al "Palmerín de Olivia”, Università de Pisa, Pisa, 1966, p. 16.

${ }^{22}$ Además de la citada referencia de Mancini, donde se encuentran investigaciones de otros estudiosos, resulta fundamental M. CARMEn MARín Pina, Edición y estudio del ciclo español de los Palmerines, tesis doctoral, Universidad de Zaragoza, 1988 (esp. pp. 191-195, donde analiza la figura del Turco como antagonista), así como su introducción a la edición de Palmerín de Olivia, ed. Giuseppe di Steffano, rev. Daniela Pierucci, CEC, Alcalá, 2004, pp. ix-xxxvii.

${ }_{23}$ Todas las citas de Palmerín de Olivia en el presente estudio proceden de la edición de Giuseppe di Steffano citada en nota anterior. 
en las naos". Tras este ataque, la imagen en Tesalia y en Duraço es de una terrible desolación: "partidos los turcos, todos los del reyno de Tesalia quedaron muy cuytados por la pérdida de su Rey como por todas las otras gentes que fueron muertas e cautivas" (p. 256), mientras que los de la ciudad de Duraço, "falláronla toda destruyda" y, tras no encontrar a la doncella, no dudaron de que había sido apresada: "como no fallarón a Laurena creyeron que yva cautiva” (p. 257). Toda esta devastación contrasta con la alegría del moro con su enorme botín. De hecho, en el capítulo siguiente, el CXX, se cuenta "cómo Olimael se tornó a la cibdad de Tubante e cómo presentó los cautivos al Gran Turco" $(i d$.$) . El éxito del capitán infiel es$ enorme: "Olimael l'embió a dezir que se aparejasse para recebir muchos cautivos cristianos que le traýa, entre los quales venían muchos altos hombres e buenos cavalleros e un Rey de los cristianos, e le traýa muchas dueñas e donzellas de muy alta guisa e mucha riqueza con ellas" (p. 258), lo que le granjea el agradecimiento del Gran Turco: "el Gran Turco fizo muy grande honrra a Olimael e díxole qu'él le galardonaría muy complidamente el gran servicio que le avía fecho" (p. 260).

Como puede comprobarse, el cautiverio de Agriola, que comienza en el capítulo LXXIV, se alarga durante buena parte del libro, lo que ayuda a crear la sensación de paso del tiempo de privación de libertad y aumenta la agonía de los cautivos, cuya liberación se demora durante un número importante de páginas. Mientras tanto Palmerín también ha de enfrentarse al peligro del cautiverio; en primer lugar cuando, tras llegar a las tierras de Babilonia, un moro intenta capturarlo, pues al oírle hablar lo identifica como cristiano: "El moro no lo entendió mas bien conoció que era cristiano en su lenguaje, e dixo: -Tú veniste a buscar tu mal, que comigo yrás cautivo, que yo cono [s]co que eres cristiano". No obstante, no lo consigue, ya que el héroe acaba con su vida, tras lo cual exclama: "Ya por vos no seré yo cautivo" (p. 164).

Si bien en esa ocasión ha evitado ese peligro, es consciente de que no está en zona de cristianos, por lo que se ve forzado a fingir ser mudo -para que no se note que desconoce el idioma del lugar- y musulmán; así logra hacerse con el favor del Soldán de Babilonia y de su hija, la hermosa Alchidiana. Finalmente, tras haber logrado coronar con éxito varias aventuras, logra escapar de esas tierras. 
Pero el riesgo del cautiverio es constante; así, tras diversas peripecias, el héroe decide partir en compañía de otros caballeros para buscar a Trineo, a Agriola y a los demás personajes cautivos, cuyo paradero el héroe desconoce; pues bien, durante la travesía marítima topan precisamente con Olimael, el temible caudillo infiel. La solución de Palmerín resulta poco caballeresca, ya que propone a sus compañeros entregarse sin luchar al infiel y ofrecerse a ayudarlo con el fin de salvar sus vidas. Efectivamente, el héroe y sus compañeros ayudarán a Olimael en sus correrías, lucharán contra los cristianos y le facilitarán que haga cautivos (entre ellos, al rey de Tesalia y a Laurena, a quienes he citado antes). De hecho, el éxito de Olimael, que iba "con infinitos cristianos cautivos e muchas riquezas" se debe a la ayuda de estos caballeros, flor de la caballería andante, cuya actitud resulta más humana y menos idealizada que en el paradigma amadisiano ${ }^{24}$. Pero no por ello estos héroes dejan de ser cautivos, como se indica claramente en la obra, pues Olimael pensaba "pedir por merced al Gran Turco que los fiziesse libres" (p. 257), lo que evidentemente implica que no son sino cautivos, y así los llama cuando aparecen ante el Gran Turco:

E él ya avía fecho sacar todas las gentes menudas cautivas e después todos los grandes hombres y cavalleros cautivos, desarmados, e después las dueñas e donzellas de muy alta guisa e después el rey de Tesalia, atadas las manos e puesta una corona en la cabeça porque conociessen que era Rey; e tras él mandó a Palmerín e a sus compañeros que fuesen todos armados salvo los yelmos e de espadas, que no le consintió llevar; e aquella honrra les fizo él porque tan bien le avían ayudado. Palmerín llevava a Laurena por la mano. E él llevava con todos estos cautivos guardas (p. 258).

El impresionante desfile de cautivos implica un orden de importancia ascendente: primero los cautivos de menor categoría, luego los caballeros y grandes hombres, tras ellos las damas de linaje, seguidas de un rey, el de Tesalia y, finalmente, Palmerín y Laurena. El héroe también desfila como cautivo, aunque

${ }^{24}$ Véase José Julio Martín Romero, "Palmerín de Olivia como enmienda del modelo amadisiano: el rechazo de la perfección arquetípica”. Esta actitud tan poco caballeresca debió de desagradar profundamente a Cervantes especialmente tras su regreso de Argel. 
el hecho de haber ayudado a Olimael le haya granjeado una situación de favor ${ }^{25}$.

En esta obra también se incide en la dureza del cautiverio, aunque siempre en consonancia con el mundo caballeresco en el que se mueven los personajes. Por ello, la imagen del rey de Tesalia avanzando entre cautivos, con las manos atadas a la espalda y coronado, detalle cruel que simplemente implica la importancia de este personaje como botín, resulta especialmente agria. No obstante, el monarca intenta mantener la dignidad y por ello se niega a besar el pie del Gran Turco, a pesar de las represalias inmediatas que sufre por ese motivo:

...el Rey de Tesalia, el qual no se quería omillar ante el Gran Turco. Olimael le dio tal puñada en el pescueço que lo fizo caer ante sus pies, e díxole:

-Lo que no quieres fazer de buen grado fazerlo has por fuerça.

El Rey, como era cavallero de tan gran coraçón, fue muy cuytado e acordó de antes morir que besar los pies al Gran Turco ni fazer cosa del mundo que deshonrra le fuesse siendo conocido por Rey, e dixo:

-Yo puedo morir mas no fazer tal offensa a mi Señor Dios que bese los pies de aquel que es enemigo de su fe.

Olimael lo quisiera matar mas el Gran Turco no quiso e mandolo quitar delante de sí e que lo llevassen luego a un castillo muy fuerte que no lo avía más en toda la Gran Turquía, e que allí lo echassen en fuertes presiones porque mayor pena le fuesse que la muerte. E ansí como lo mandó fue fecho (p. 259).

La actitud llena de dignidad del rey de Tesalia se contrapone con la de Palmerín, acomodaticia y pragmática, tal como ha sido hasta ese momento, de manera que no sorprende que él sí acepte besar los pies del Gran Turco: "Palmerín no quiso dar a conocer que era de alto linaje mas luego se abaxó a besar los pies al Gran Turco, como todos fazían" (id.).

La situación indigna de los cautivos se evidencia también cuando otro personaje, Tolomé, tiene que soportar ser golpeado de forma injusta por su amo. Cuando la cautiva Agriola ve

${ }^{25}$ El propio Olimael afirma ante el Gran Turco que son cautivos: "éstos fueron los primeros cristianos que yo cautivé, e tomelos en la mar e ellos me juraron de ser leales e me ayudar e ansí lo han fecho" (p. 259), por lo que le ruega que les dé la libertad. Por tanto, son tan cautivos como los demás, pues sólo han sacrificado sus valores para proteger su vida y favorecer su propia liberación. 
que también han apresado a Tolomé, no puede por menos que echarse a llorar, lo que hace pensar a su amo Olimael que este hombre ha causado ese dolor a la dama, y no duda por ello ordenar golpearlo; el cristiano ha de tragarse el orgullo y soportar estoicamente esa humillación:

Olimael fue muy ayrado por ver llorar a Agriola e mandó ferir a Tolomé, que jamás paresçiesse delante d'ella. E luego fue fecho. Tolomé era de gran coraçón e sesudo e sofriolo con grande paciencia, que bien vido que no era tiempo de otra cosa (p. 161).

Este personaje pasará por las manos de diversos amos, el último de los cuales lo tratará bien, pero no así su mujer, a causa de que Tolomé le reprochó que fuera infiel a su marido. A la muerte de éste, su ama, despechada, a Tolomé y a su amigo Colmelio "fízoles atar las manos e llevarlos a vender a la corte del Soldán"; entre quienes intentan comprarlo se encuentra un herrero "muy chiquito de cuerpo e venía muy suzio del cisco de su fragua", al que Tolomé ataca para evitar "venir en poder de tal vil cosa" (p. 280). Por fortuna, la hija del Soldán, Alchidiana, lo rescata de esa situación embarazosa ${ }^{26}$.

Como puede verse, la importancia del cautiverio es enorme en Palmerín de Olivia; y es que no hay que olvidar que esta obra se compuso en unos años en los que se incrementó el número de ataques berberiscos y eran, por tanto, una preocupación real $^{27}$. La actitud política ante los musulmanes cambió con las nuevas ideas de Cisneros sobre este tema, como ha indicado García Cárcel: precisamente en 1511, fecha de la publicación de Palmerín de Olivia, la toma de Trípoli intentaba frenar los avances berberiscos ${ }^{28}$. Este investigador considera que la etapa

${ }^{26}$ Será en ese momento cuando Alchidiana se entere de que Palmerín, que estuvo en su corte y del que se enamoró, no era moro, como fingía, sino que "él negó la verdad por no ser cativado" (p. 281).

${ }_{27}$ Cf. Cesáreo Fernández Duro en su Historia de la Armada Española desde la unión de Castilla y de León, Imprenta Real, Madrid, 1895-1903, t. 1, pp. 65-75.

28 "El viraje de la estrategia pastoral seguida con los musulmanes después de la conquista de Granada de 1492, con el paso de la línea tolerante y permisiva de Talavera a la dura e inflexible de Cisneros, está evidentemente relacionado con el problema africano, por el constante flujo de musulmanes de uno y otro lado del Estrecho. Cisneros, durante su primera regencia, tomó el Peñón de Vélez en 1508 y Orán y Bujía en 1510 y se intentó formar una Liga Santa contra los turcos. El capitán Pedro Navarro, a las órdenes del Rey Católico, tomaría Trípoli en 1511. Las correrías de los piratas berberiscos, 
de 1492 hasta 1540 puede considerarse como una "de política agresiva de España en el Mediterráneo" 29.

Por otra parte, el hecho de que Palmerín sea heredero del trono de Constantinopla (en tanto que hijo de Griana, la hija del emperador) quizá pueda relacionarse con la nostalgia cristiana ante la pérdida de esa ciudad en manos infieles y su conversión, por cierto, en un importante centro de cautiverio durante el siglo $\mathrm{XVI}^{30}$. Quizá la ficción pretendía recuperar para los lectores cristianos, aunque en el entorno de la fabulación, el Imperio de Oriente ${ }^{31}$. Todo esto nos puede hacer recapacitar sobre la vinculación entre historia y ficción caballeresca, mucho más de lo que hasta ahora se ha afirmado.

En cualquier caso, en Palmerín de Olivia el reflejo de las razias de los corsarios al servicio del Gran Turco resulta más realista que el reflejo del infiel en otros libros de caballerías. Si comparamos los episodios aludidos de esta obra con las andanzas del protagonista de Belianis de Grecia -por cierto, otro heredero de Constantinopla- en tierras orientales, descubriremos que Jerónimo Fernández en este libro presentaba a los musulmanes con los mismos rasgos caballerescos que a los cristianos, como sucede, entre otras obras, en el Abencerraje. Aunque los cristianos ocultan su religión en esas tierras, respetan a los caballeros (que como tales se presentan) infieles y grandes señores orien-

al frente de los cuales estaba Barbarroja, seguían haciendo mucho daño a las galeras españolas" (Ricardo García CÁrcel, "La psicosis del turco en la España del Siglo de Oro", en Los imperios orientales en el teatro del Siglo de Oro. Actas de las XVI Jornadas de teatro clásico, Almagro, julio de 1993, eds. F. B. Pedraza Jiménez y R. González Cañal, Universidad de Castilla La Mancha, Almagro, 1994, p. 6).

${ }^{29}$ GARCía CÁrcel, art. cit., p. 16. Esta etapa parece recrudecerse a partir de 1499: "a partir de 1499, los Reyes Católicos rompen los compromisos contraídos con los musulmanes previamente a la rendición de Granada y Cisneros deshace en meses la política tolerante y permisiva de Talavera" $(i d$.).

30 Ricardo González Castrillo, "Cautivos españoles evadidos de Constantinopla en el siglo xvi”, Anaquel de Estudios Árabes, Madrid, 22 (2011), 265-278.

31 Sobre Constantinopla como tema literario, L. Stegnano Picchio, "Fortuna iberica di un topos letterario: La corte di Constantinopoli del Cligés al Palmerín de Olivia", Studi sul Palmerín de Olivia. III. Saggi e ricerche, Università, Pisa, 1966, pp. 99-136. Por su parte, Emilio Sales Dasí ha estudiado este tema en dos libros del ciclo amadisiano en "De Constantinopla y otras marcas identificadoras del Florisando y el Lisuarte de Grecia", Tirant. Butlleti Informativ $i$ Bibliográfic de Literatura de Cavalleries, Valencia, 5 (2002), en http:/ / parnaseo. uv.es/Tirant/Butlleti.5/sales.htm. 
tales, que son reflejados llenos de autoridad y virtudes. Frente a esto, en Palmerín de Olivia se constata el antagonismo entre los que practican la fe cristiana y los que profesan el Islam ${ }^{32}$.

En definitiva, en esta obra encontramos antecedentes claros del tema del cautiverio tal como se tratará en obras posteriores; su enorme éxito y difusión hacen difícil aceptar que no influyera en la forma como autores posteriores tratarán este tema, con Cervantes, ávido lector de libros de caballerías, a la cabeza.

Es más, en Palmerín de Olivia también pueden detectarse trazos y tramas que pudieron ayudar a configurar uno de los episodios que Cervantes incluyó en varias de sus obras que tratan el tema del cautiverio: el cruce de enamoramientos entre amos infieles y esclavos cristianos, y la solicitud de que éstos hagan de medianeros o terceros en estas relaciones. La reaparición de este tema en varios títulos cervantinos es un interesante caso de reescritura de la propia obra, algo muy frecuente en Cervantes, como ha estudiado Antonio Rey Hazas, y que, además, se constata como una práctica habitual en la narrativa áurea, como indiqué en otra ocasión ${ }^{33}$.

La trama a la que he aludido ha sido objeto de estudio por parte de Zimic, que determinó los dos rasgos propios de este tema: "el amante celestino" y "los amores cruzados". Asimismo estableció su fuente fundamental: la obra de Aquiles Tacio Leucipe y Clitofonte, que Cervantes pudo conocer en la traducción italiana de Angelo Coccio impresa en 1551, así como la versión castellana que se lee en Clareo y Florisea de Núñez de Reinoso, (que, a su vez, procede de la versión italiana de Dolce, los Razonamientos de amor $)^{34}$. Zimic indica que seguramente Núñez de

${ }^{32}$ Lo cual no impide que algún personaje infiel (Olorique) destaque por su carácter caballeresco y establezca una amistad duradera con Palmerín.

33 Sobre la reescritura de la propia obra por parte de Cervantes, véase Antonio Rey Hazas, "Cervantes se reescribe: teatro y Novelas ejemplares", Criticón, 76 (1999), 119-164; por mi parte, estudio el ejemplo de esta práctica a finales del siglo xvi al analizar la obra de Pedro de la Sierra, que la lleva a cabo incluso en el interior de un único texto. Véase José Julio Martín Romero, Entre el Renacimiento y el Barroco. Pedro de la Sierra y su obra, Prensas Universitarias, Zaragoza, 2007, pp. 243-254.

34 Christine Marguet, "De Leucipa y Clitofonte de Aquiles Tacio a la Historia de los amores de Clareo y Florisea de Alonso Núñez de Reinoso: un caso de reescritura novelesca entre traducción y creación”, Criticón, 76 (1999), 9-22. Véase, asimismo, los comentarios y las abundantes notas de José JiménEZ Ruiz a su edición de Alonso Núñez de Reinoso, Historia de los amores de Clareo y Florisea, Universidad, Málaga, 1997. 
Reinoso también conoció la traducción italiana de la obra de Aquiles Tacio ${ }^{35}$. De hecho, el investigador considera que la primacía de esta trama en la literatura española se ha de conceder precisamente a Núñez de Reinoso, quien, tomándola de Aquiles Tacio y Ludovico Dolce, la incorporó a su obra ${ }^{36}$.

Por mi parte, considero que a los rasgos mencionados por Zimic habría que añadir otro: la función principal del fingimiento o del engaño, medio que permite a los cristianos dominar una situación cuando menos compleja.

Esta historia se encuentra en El trato de Argel, lo que, por otra parte, no sorprende demasiado, ya que esta pieza teatral parece ser el germen de Los baños, a pesar de las diferencias que existen entre ellas y que fueron mencionadas por Casalduero y estudiadas con más detenimiento por Meregalli ${ }^{37}$. Como es sabido, esta trama reaparecerá en El amante liberal, así como en el Persiles, aunque, como indicó Zimic, con notables diferencias ${ }^{38}$.

Como he indicado, junto a las fuentes comentadas por Zimic, también hay que considerar la influencia que en la configuración de esta trama ejerció Palmerín de Olivia.

En primer lugar, conviene recordar los rasgos fundamentales de esta trama en las obras cervantinas. Como es sabido, dos amantes se hallan cautivos en tierras de infieles y despiertan el amor respectivamente en su ama y amo, quienes ignoran la relación amorosa que existe entre sus esclavos. Éstos se proponen aprovechar esa circunstancia para su propio beneficio. De esta manera, deciden que se ofrecerán a servir de mensajeros o alcahuetes, si bien, como es esperable, no se trata sino de un fingimiento, una estratagema para poder verse a solas y organizar su huida. En definitiva, utilizan los sentimientos que han despertado en sus amos para manipularlos y así poder escapar.

35 Stanislav Zimic, "El amante celestino y los amores entrecruzados en algunas obras cervantinas", BBMP, 40 (1964), 361-387.

36 Ibid., p. 364.

37 Joaquín Gimeno Casalduero indicó la semejanza y destacó algunas diferencias (Sentido y forma del teatro de Cervantes, Gredos, Madrid, 1974, pp. 77 y ss.); por su parte, Franco Meregalli realizó una comparación más exhaustiva de estas dos piezas dramáticas en su artículo citado "De Los tratos de Argel a Los baños de Argel".

${ }^{38}$ Indica que Cervantes abandona la "fórmula perfectamente simétrica de amores" y que el papel de tercería desempeñado por Auristela es profundamente diferente al de los personajes de las obras anteriores, y propone que ello se debe a que Cervantes ya no utilizaba la trama para marcar la oposición establecida entre Cristianismo e Islam (ZıмIC, art. cit., pp. 385-387). 
El hecho de actuar como alcahuete del propio cónyuge (o fingir hacerlo) también aparece en Ozmín y Daraja, que Mateo Alemán incluyó, como es sabido, en su Guzmán de Alfarache. Ya Navarro Durán señaló algunos puntos para demostrar que esta novela de Mateo Alemán fue utilizada como fuente por Cervantes y mencionó expresamente su influencia en $\mathrm{El}$ amante libe$\mathrm{ral}^{39}$. Navarro Durán analiza con acierto un número importante de semejanzas, aunque no trata la trama de amante celestino, que también se da en la novela de Mateo Alemán, pues Ozmín finge hacer de medianero de su propia esposa, miente y disimula entre los que practican una fe distinta a la suya y se aprovecha del amor que su esposa despierta en otros, aunque lamenta la situación poco honrosa: "No sabré decir ni se podrá encarecer lo que sintió verse hacer segunda vez alcahuete de su esposa y cuánto le convenía pasar por todo con discreta disimulación" ${ }^{40}$.

Ciertamente no hay que olvidar que esa trama aparece ya en El trato de Argel, anterior a la primera parte del Guzmán. No obstante, no es imposible que la lectura de Ozmin y Daraja se mezclara en el magín cervantino con la influencia de su propia producción y dejara algún tipo de impronta en esta trama, tal como se desarrolla en sus obras posteriores. Pero no es mi intención analizar aquí esta cuestión, sino buscar antecedentes caballerescos de estas historias sobre fingimientos y disimulos cristianos en tierras de infieles.

Es cierto que el engaño a musulmanes por parte de cautivos cristianos es un motivo frecuente en los libros de caballerías del Renacimiento; ya desde sus primeros títulos aparecen numerosos episodios de este tipo: además de en Palmerín de Olivia (1510), también sucede en diversas entregas amadisianas de Feliciano de Silva, especialmente en las distintas partes de Florisel de Niquea. Aunque sin el tema del cautiverio, este disimulo de cristianos en tierras infieles es la base argumental de casi toda la primera parte de Belianis de Grecia (1547), por poner tan sólo unos ejemplos de libros de caballerías de éxito y cuya lectura por parte de Cervantes es asunto probado.

Pero lo que más me interesa es destacar la relación entre algunos episodios de Palmerín de Olivia y la trama de engaño y

39 Rosa Navarro Durán, "La historia de Los dos enamorados Ozmín y Daraja, fuente de inspiración cervantina”, RFE, 82 (2002), 87-103.

40 Mateo Alemán, Guzmán de Alfarache, ed.J.M. Micó, Cátedra, Madrid, 2000, t. 1, p. 234. 
fingimiento de Fernando y Costanza, vinculada con el tema del "amante celestino" del que habló Zimic.

En Palmerín de Olivia, entre los varios personajes que caen en manos infieles se encuentra Agriola, hija del rey de Inglaterra. $\mathrm{Su}$ amo, el Gran Turco, cae rendido ante su belleza, pero ella rechaza todos los avances eróticos del infiel ${ }^{41}$. En un momento determinado Agriola se encuentra con Palmerín, que también ha sido hecho cautivo, amigo de su amado Trineo. La turbación de la dama no pasa desapercibida al Gran Turco, que piensa que es su marido. Ella intenta disipar cualquier sospecha al respecto; para conseguirlo no duda en mentir y decir que se trata de su hermano:

Agriola, que cerca del Gran Turco estava, como vos deximos, conoció luego a Palmerín e fue tal parada que a pocas no morió... El Gran Turco, como le vido fablar, luego conoció que por amor d'él le avía venido aquella alteración e pensó que era su marido, como ella muchas vezes lo avía dicho, e pensó de matarlo... Agriola se abraçó con él, diziéndole: “Ay mi señor, por Dios no fagáys tal!, que yo vos juro por la fe que a Dios e a vos devo qu'él es mi hermano e me venía a buscar; e sabed que si él muere, que yo moriré también" (p. 259).

Por tanto, los cristianos se ven obligados a explicar ante sus amos infieles una determinada reacción, para lo cual no dudan en fingir y mentir. Una situación parecida encontramos en Los baños de Argel, cuando don Fernando y Costanza se abrazan, momento en que sus amos los descubren y, celosos, los amenazan duramente. En esta comedia cervantina, los cristianos se justifican así:

41 Esta situación aparece en numerosas ocasiones en la obra cervantina. De hecho, ya Jean Canavaggio comentó, al hablar de la Gran Sultana cervantina, que la tradición del tema de la cristiana cautiva de la que se enamora su amo contaba con el antecedente de uno de los episodios de Palmerín de Olivia, aunque no lo considera propiamente una fuente: "Sans aller jusqu'à tenir cet épisode pour un «source» de la pièce, on peut néanmoins admettre une parenté certaine entre la fable cervantine et un récit bien connu du dramaturge et où, de surcroît, se dessinent, comme le remarque Albert Mas, «les grandes lignes des futures turqueries»" (en Cervantès dramaturge. Un théâtre à naître, Presses Universitaires de France, Paris, 1977, p. 58; sobre la cita de MAs, véase la n. 14). 
D. [FER.] ¡Oh, cuán mal está entendida, señores, nuestra intención!

Aquel abrazo que viste, Costanza a ti le enviaba.

COSTAN. En tu nombre se fraguaba el favor que interrumpiste (p. 958b).

En El trato de Argel ya se encontraba la misma situación: Aurelio y Silvia son descubiertos por sus amos mientras se abrazaban, situación peligrosa que Aurelio salva con la siguiente explicación:

AUREL. No, por cierto, señores; no ha nacido nuestra desenvoltura de ocasiones lascivas, según da las muestras dello, sino que a Silvia le rogaba ahora me hiciese una merced que ha muchos días que se la pido, y no por mi interese; y ella también a mí me ha persuadido un servicio le hiciese que conviene para mejor servir la casa vuestra.

$\mathrm{Y}$, por habernos concedido entrambos aquello que pedía el uno al otro, en señal de contento nos hallastes de aquel modo que vistes abrazados, sin manchar los honestos pensamientos ${ }^{42}$.

Por tanto, la situación resulta muy parecida en Palmerín de Olivia y en las comedias cervantinas, pues en todos estos textos los cautivos cristianos (un hombre y una mujer, aunque en el caso del libro de caballerías no se trata de amantes) han de mentir cuando sus amos sospechan que mantienen una relación sentimental; si bien en Palmerín -frente a las obras cervantinasno existe esa relación, fingir que son hermanos -lugar común de la fuente bizantina ${ }^{43}$ - ayuda a disipar esas sospechas.

42 El trato de Argel, en Miguel de Cervantes, Obras completas, ed. F. Sevilla Arroyo, p. 844b. Todas las citas a esta comedia en el presente estudio proceden de esta edición.

${ }^{43}$ Véase Christine Marguet, “«Los hermanos amantes»: des relations entre homme et femme dans le roman byzantin”, en Relations entre hommes et femmes en Espagne aux XVI et XVII siècles, éd. A. Redondo, Presses de la Sorbonne Nouvelle, Paris, 1995, pp. 167-176. 
En el libro de caballerías, el infiel decide aprovecharse de esa supuesta relación fraternal para lograr sus deseos con la dama y le propone al fingido hermano que haga de celestino:

Yo creo bien que voys soys hermano de mi señora Agriola, que muy bien vos parecéys en la fermosura. E pues que Dios vos traxo a esta tierra, ruégovos que trabajéys con ella que me ame más que fasta aquí ha fecho e consienta que yo goze d'ella a mi voluntad, que si yo de ella uviesse fijos tendríame por muy bienandante. $\mathrm{E}$ yo vos prometo, si estoy fazéys, de fazervos el mayor hombre que hay en toda mi tierra (p. 260b).

Obsérvese cómo el personaje cree que son hermanos, porque encuentra un claro parecido físico entre la dama y el héroe. Esto se explica como resultado de los postulados neoplatónicos que defendían que la belleza era única y que se reflejaba en distintos seres y objetos. Cuanto más cercanos a esa belleza ideal, tanto más hermosos resultaban, puesto que se propone a los personajes cristianos como enormemente bellos, comparten esa semejanza con la idea única de belleza y, por tanto, se parecen entre $\mathbf{s i ́}^{44}$.

En cualquier caso, la enorme hermosura de Agriola se convierte en el punto flaco del Gran Turco. Palmerín ve la oportunidad que esa debilidad supone y se ofrece a ayudarlo, aunque en su fuero interno no piensa hacerlo, más bien se trata de un disimulo para lograr ventaja y organizar su huida: "Yo soy muy contento qu'ella sea vuestra e punaré quanto pudiere que ella faga vuestro mandado... E cierto, señor, creed que yo faré todo lo que pudiere en este caso" (p. 260b). Una situación ciertamente parecida encontramos en Los baños de Argel, cuando Cauralí, amo de Costanza, pide a don Fernando que lo ayude a conseguir el amor de la dama:

CAUR. $\quad$ Ella es hermosa en estremo; mas llega a su hermosura

${ }^{44}$ Sobre el neoplatonismo en los libros de caballerías y su importancia en la caracterización del héroe, véase José Julio Martín Romero, "Reflejos de Diana en el cuerpo de Febo: imitación poética y neoplatonismo en la écfrasis de un héroe caballeresco", Destiempos, México, 2009-10, núm. 23, 182-201. Sobre el neoplatonismo y el amor en los textos caballerescos, José Julio MARTín ROMERo, "Del fin' amors al neoplatonismo: amor y caballería en la narrativa caballeresca hispánica”, Tirant. Butlletín informativ i bibliográfic de Literatura de Cavalleries, Valencia, 11 (2009), 119-142. 
su riguridad, que temo.

¡Ya, amor, desta piedra dura saca el fuego en que me quemo!

Hete dado cuenta desto, para que en mi gusto el resto eches de tu discreción.

A lo que Fernando finge acceder y estar dispuesto a todo por complacer a su amo, tal como hizo Palmerín en el libro de caballerías:

D. [FER.] Más pide la obligación, buen señor, en que me has puesto.

Muéstrame tú la cautiva;

que, aunque más esenta viva del grado poder de amor, la has de ver de tu dolor, o amorosa, o compasiva

$$
\text { (pp. 949b-950a). }
$$

La situación es paralela a la de El trato de Argel, con la que Los baños presenta, como es sabido, numerosas concomitancias:

YZUF: $\quad$ y desde aquí te prometo que, si conduces a efeto mi amorosa voluntad, de darte la libertad

$\begin{array}{ll}\text { AUREL. } & \text { y serte amigo perfeto. } \\ \text { En todo lo que quisieres, }\end{array}$ he, señor, de complacerte, por ser tu esclavo y por verte que melindres de mujeres te tengan de aquesa suerte (p. 833).

En el libro de caballerías, Agriola, aunque sigue rechazando sus avances, se muestra menos arisca con el fin de apaciguarlo y manejarlo: "Agriola le mostró más amor que fasta allí porque le diesse lugar que pudiesse hablar con Palmerín” (p. 261a). El autor repite la idea insistiendo en que es un afecto fingido: " $\mathrm{E}$ a la noche Agriola mostró grande amor al Gran Turco por engañarle, mas no le consintió fazer más de lo que ella quiso e ovo gana; e rogole muy afincadamente que fiziesse grande honrra 
a su hermano porque él uviesse gana d'estar en aquella tierra" (p. 261b). Esto permite a Palmerín conseguir que el Gran Turco libere la nao en que vino, así como a los marineros, a quienes el caballero ordena secretamente que aguarden. Cuando Palmerín va a hablar con Agriola, la acompaña Ypólita, quien, como la dama advierte al héroe, comprende su idioma, por lo que le avisa que no hable de manera clara de sus propósitos y enganos. Por cierto, que esta situación recuerda a otra de El amante liberal, en la que Leonisa advierte a su amigo de que puede estar oyéndolos su ama ${ }^{45}$. Tras esta entrevista, Palmerín le dice al Gran Turco que ha estado intentando convencer a la dama de que acepte su amor: "Palmerín se fue para el Gran Turco e díxole como avía estado con su hermana e le avía rogado que fiziesse su mandado. Él gelo agradesció e de allí adelante fazíale grandes onrra e dávale muy grandes dones" (p. 262a).

Otra dama, Laurena, los ayuda fingiendo aceptar el amor del Gran Turco con el propósito de que éste relaje la vigilancia sobre Agriola: "Laurena, que muy entendida era, pensó en su coraçón que por aquel camino tendrían manera de yrse de aquella tierra e aver vengança d'él, que tanto mal avía venido a su causa a los cristianos e más a ella e a su padre" (pp. 263b-264a). Por este motivo, se muestra más cariñosa con el Gran Turco, con el fin de que no sospechara el engaño: "E mostrole grande amor aquella noche por más engañalle” (p. 265a). Cuando llega la noche en que el Gran Turco espera en su lecho a la doncella para satisfacer sus deseos, quien llega en realidad es otro caballero, el Duque de Ponte, que acaba con el infiel y le corta la cabeza, que después muestra como trofeo a las damas con las siguientes palabras jocosas: "Señoras, vedes aquí vuestro amigo: si vos amó llorad su muerte en galardón, que vos a él malo gelo distes" $(i d .)^{46}$. Estos engaños les permitirán embarcar en la nao preparada a tal efecto y huir en ella. Precisamente es la forma

45 "Púsose Leonisa enesto el dedo en la boca, por lo cual entendió Ricardo que era señal de que callase o hablase más quedo". La dama le dice a Ricardo: "Habla paso, Mario, que así me parece que te llamas ahora, y no trates de otra cosa de la que yo te tratare; y advierte que podría ser que el habernos oído fuese parte para que nunca nos volviésemos a ver. Halima, nuestra ama, creo que nos escucha..." (El amante liberal, en Miguel De CERvanTES, Obras completas, ed. F. Sevilla Arroyo, p. 550). Todas las citas de esta obra en el presente estudio proceden de esta edición.

${ }^{46}$ Quizá se trate de un recuerdo de Judith y Holofernes, pues si bien en este caso no es la dama quien acaba con el lascivo personaje, éste muere en la cama a manos de quien piensa que lo es. 
como concluye también la comedia de Los baños de Argel, con la huida por mar, tras haber sido engañados los amos, aunque -frente a lo que sucede en el libro de caballerías- sin que ninguno de éstos muera ${ }^{47}$.

Por otra parte, quizá también puedan detectarse ecos de Palmerín de Olivia en El amante liberal. En el libro de caballerías, la dama cae en manos de Olimael, quien intenta satisfacer sus deseos carnales con ella, pero de forma infructuosa, por lo cual decide entregársela al Gran Turco, cuya lascivia era bien conocida. Esto parece recordar la situación de la dama en la citada novela ejemplar, en la que la doncella pasa a manos de un judío que, prendado de su belleza, intenta poseerla, pero la férrea voluntad de la dama impide que cumpla sus deseos, de manera que decide venderla, despertando el libidinoso interés de Alí y de Hazán, quienes, so pretexto de querer entregarla al Gran Turco, intentarán por todos los medios hacerse con ella, aunque sin éxito, pues el Cadí decide ser él quien haga la entrega, aunque en su fuero interno tiene las mismas intenciones rijosas que los otros $\operatorname{dos}^{48}$. Por tanto, Palmerín y la novela ejemplar coinciden en algunos puntos: 1) la dama cae en manos de un amo que 2) intenta satisfacer su lujuria con ella, pero 3) sin ningún éxito debido a que la mujer se niega, de forma que 4) decide dar mejor uso a su cautiva, vendiéndola o entregándola a un gran señor infiel.

En estos casos la dama ha de defender con brío su honestidad, si bien Agriola, en el libro de caballerías, cuenta con un anillo encantado que impide que ningún hombre pueda forzarla. Cuando lo intentaron Olimael y el Gran Turco sufrieron una especie de paroxismo, de manera que se vieron obligados a cejar en su empeño. El recurso a la magia, propio de los textos caballerescos, puede resultar bien distinto del carácter "realista" del tema del cautiverio en la obra cervantina, pero quizá sea todavía menos creíble que el brío y la fuerza de la dama en las obras del alcalaíno pudieran evitar que sus rijosos amos satisficieran sus deseos. Recordemos las dudas en este sentido que se leen en Leucipe y Clitofonte, cuando Tersandro no cree que Leucipe siga virgen tras haber pasado por manos de tantos

47 Como es sabido, el desenlace es distinto en El trato de Argel, pues los esclavos amantes son liberados por el rey de los turcos.

48 El amante liberal, ed. cit., pp. 546-547. 
corsarios, dato que comentó Zimic ${ }^{49}$. Esta duda tan razonable también fue recogida por Núñez de Reinoso en su Clareo y Florisea: "¿Donzella tú -dixe Thesiandro- haviendo andado entre cossarios? Por Dios que sí, sino si por ventura se tornaron eunucos o philósophos" $"$.

En este sentido, la honestidad de las doncellas cervantinas a prueba de la fuerza bruta quizá pueda ser percibida como algo tan poco probable como la existencia de un anillo encantado. En cualquier caso, psicológicamente los amos infieles de libros de caballerías resultan mucho más creíbles que los pudorosos amos cervantinos, que parecen aceptar la negativa de sus cautivas sin oponer excesiva resistencia.

En definitiva, como puede observarse, existe una serie de coincidencias entre el libro de caballerías y las obras cervantinas:

1) Unos cristianos cautivos en tierras infieles.

2) Se aprovechan de los sentimientos amorosos que alguno o algunos de ellos despiertan en su amo (o amos).

3) Se ven obligados a explicar una muestra de emoción (turbación/abrazo) que hace pensar a sus amos que son amantes.

4) Por ello fingen tener una relación distinta a la real para disipar toda sospecha.

5) Se produce un fingido ofrecimiento a actuar como mensajero amoroso para el amo infiel.

6) Finalmente se aprovechan de sus engaños para poder escapar.

Es evidente, sin embargo, que en Palmerín de Olivia no se produce el cruce de deseos que se da en Los baños de Argel, donde el ama se enamora de Fernando y el amo, de Costanza. En el libro de caballerías, sólo el amo, el Gran Turco, se enamora de la cristiana. No obstante, y aunque no sucede en el mismo momento, también Palmerín se ve obligado a fingir amor a su ama infiel, la hermosa Alchidiana, y aprovecharse de esos sentimientos para evitar el peligro; llega (como harán otros caballeros andantes en libros de caballerías posteriores) a fingir no ser cristiano y mentir de forma abierta para proteger la vida. En realidad, se trata de acontecimientos que suceden de forma casi

49 "Tu... sei vergine? O audacia degna di risa... tu... che tante notti sei stata tra tanti corsali? Sono essi stati eunuchi per te? ...niuno di loro hebbe ochi?" (Apud. Zıмıc, "El amante celestino...", p. 369).

50 Alonso Núñez de Reinoso, Historia de los amores de Clareo y Florisea..., ed. J. Jiménez Ruiz, Universidad, Málaga, 1997, p. 162. 
simultánea; en cualquier caso, resulta evidente que, aunque en espacios diferentes, se produce algo parecido al quiasmo cervantino, siempre teniendo en cuenta que Palmerín y Agriola no son amantes.

De todas formas, tanto en el libro de caballerías como en Los baños de Argel la dama infiel se enamora perdidamente del caballero cristiano, hasta tal punto que pierde la vergüenza y se declara. Esto es tanto más llamativo en Los baños cuanto que el caballero es un cautivo, mientras que en Palmerín el héroe no es tal, pues finge incluso que profesa la fe musulmana. En cualquier caso, aunque este caballero evita el peligro con mentiras y disimulos, no puede dejar de sentirse cautivo, por mucho que Alchidiana no sea consciente.

Pues bien, esta dama cae rendida ante la belleza del héroe en cuanto lo ve: "antes pareció que desde aquella ora su coraçón lo començó de amar muy afincadamente" (p. 167); de forma que, cuando el héroe se hace pasar por mudo para evitar ser reconocido por su habla extranjera, "Alchidiana nunca pudo dormir toda la noche pensando en el mudo" (p. 168) ${ }^{51}$. A Palmerín no se le escapa la debilidad que la dama siente por él ("e dio muchas gracias a Nuestro Señor por le aver dado gracia con aquella donzella", $i d.)^{52}$. Pronto es evidente el enamoramiento de la dama y sus palabras no pueden ocultar sus sentimientos:

Aquel día mostró Alchidiana grande amor a Palmerín e dezíale: ¡Ay el mi cavallero mudo, cómo valéys vos más que todos los del mundo! No sé yo por qué Dios e Mahoma vos quitaron la habla, pues en todas las otras cosas tan complido vos fizieron (p. 173).

Esto lleva a la doncella a declarar abiertamente su amor al caballero, prácticamente segura de que no la rechazará: "quiero que mi coraçón fuelgue con vos e de aquí adelante doyvos

51 Lo que Alchidiana teme es que Palmerín pierda la vida, pues ha sido condenado a ser entregado a los leones a causa de haber matado a varios moros. El Soldán, padre de la doncella, a petición de ésta, accedió a no mantenerlo encerrado con los leones, pero no pudo evitar que pasara por ese peligro, pues había dado su palabra.

52 El texto indica que Palmerín considera que el hecho de que la doncella quiera salvarlo de los leones se debe a la intervención divina, que Alchidiana es un medio de Dios para salvarlo, por lo que agradece a Dios los favores que consigue por medio de ella. Se trata de una manera de incidir en el cristianismo del héroe, cuya religiosidad aquí y en otros muchos momentos del libro queda en entredicho. 
licencia que fagáys de mí como de cosa vuestra, qu'el coraçón vos ama tanto que no puedo ál fazer" (p. 175). Cuando Palmerín no demuestra el interés que ella espera, la sospecha de ser rechazada la atormenta:

¡Ay cabtiva, cómo soy de malaventura, siendo una donzella tan alta como yo -que otra mayor no la hay en el mundo-e poner mi coraçón en un cavallero que no sé quién es, mudo, que no me entiende ni me puede hablar, e lo peor es que me desprecia, que no quiere mi amor! (id.).

Aunque lucha contra sus sentimientos, no puede evitarlos: "que ansí como lo vido delante de sí parescíale tan bien que perdía toda la yra que contra él tenía" (p. 176), aunque "antes le mostrava alguna parte de su enojo e no le dava tantos dones como solía ni le fazía tanta honrra" (id.). No obstante, los sentimientos son de tal magnitud que no puede por menos que volver a declararse a Palmerín -una vez éste (finge que) ha recuperado la voz- y le reprocha que la fuerce a comportarse de forma tan poco honesta: "ya por dos vezes he puesto mi vergüença delante de vós... no esperéys que yo más sea la desvergonzada" (p. 183). Ante esta situación, el héroe intenta ganar tiempo y finge aceptar su amor: "acordó de responder lo mejor que él pudiesse para contentalla pues tan çedo se avía de yr de aquella tierra" $(i d$.$) . Para ganar tiempo, le solicita entonces un$ plazo, supuestamente para poder adquirir honra que le haga merecedor de ella:

Yo tengo razón de amaros e servíos más que a ninguna donzella que hay en el mundo e ansí lo faré; e tanto quanto yo más os amo es razón que cate vuestra honrra... yo entiendo de fazer tales servicios a vuestro padre qu'él aya por bien, quando viniere, de fazerme esta merced, rogándoselo vos. E fasta entonces conviénenos de sofrir nuestros deseos porque después podamos bevir muy descansados para siempre (p. 184).

En Los baños de Argel, el cautivo Fernando despierta el amor de su ama Halima, cuyos sentimientos son, al igual que los de Alchidiana, tan fuertes que no puede evitar perder la compostura y declarar su amor al caballero, con un tono de reproche que recuerda la actitud de la dama en el libro de caballerías cuando no encontró la reacción que ella esperaba en Palmerín: 


\author{
¿Pues cómo, inhumano? \\ ¿Nunca te han dicho mis ojos \\ y la lengua de Costanza \\ que tienes de mi esperanza \\ en tu poder los despojos? \\ ¿Has aguardado a que haga \\ de tanta gente en presencia \\ esta costosa experiencia \\ descubriéndote mi llama? \\ Mira qué fe desdichada, \\ que esto que llaman amor \\ ya es incendio, ya es furor, \\ cuando no repara en nada; \\ mira bien que podría ser, \\ si desprecias lo que digo, \\ hicieses, hombre, enemigo \\ de tan amiga mujer
}

(p. 970b).

En las palabras de Halima se descubren los mismos sentimientos que en Alchidiana, el amor que la lleva a proteger al hombre que ama, a ser, como la dama del libro de caballerías, "desvergonzada", a declarar sus sentimientos al caballero y a amenazarlo cuando no descubre la reacción esperada en él. También en El trato de Argel Zahara, ama de Aurelio, muestra un apasionado ardor por su cautivo ${ }^{53}$. Asimismo, en El amante liberal se cuenta cómo Halima cae rendida ante el cautivo Mario (que, en ese momento, tampoco es amante de Leonisa):

Avino, pues, que un día la señora Halima vio a su esclavo Mario, y tan visto y mirado fue, que se le quedó grabado en el coraçón y fijo en la memoria; y, quizá poco contenta de los abrazos flojos de su anciano marido, con facilidad dio lugar a un mal deseo, y con la misma dio cuenta dél a Leonisa (p. 549b).

Se observa que no sólo pide a Leonisa que actúe de medianera en sus amores, sino que Cervantes indique la "facilidad" con que nació el deseo (psicológicamente justificado, aunque en forma de hipótesis por la ancianidad de su marido y sus "abrazos flojos") y lo fácil que también le resultó confesar ese "mal deseo" a

53 Así, en El trato de Argel, cuando Aurelio intenta escabullirse ante el arrojo erótico de la dama bajo pretexto de ir a buscar agua, ella afirma sin empacho: "Otra agua pide mi fuego / que no la que tú trairás" (p. 828a). 
Leonisa, es decir, que Halima resulta tan "desvergonzada" como su homónima en la comedia Los baños de Argel, como Zahara en El trato, y, por tanto, todas coinciden con la actitud de Alchididana en Palmerín.

Si volvemos a la comedia cervantina, resulta significativo que Fernando, ante estas palabras, reaccione de igual manera que Palmerín: finge aceptar los requerimientos amorosos de la dama infiel, dama que está en una posición de superioridad frente a él, y le pide un plazo para satisfacerla, un plazo que en realidad le permita escapar:

$$
\begin{aligned}
& \text { Tres días pido, no más } \\
& \text { de plazo, señora mía } \\
& \text { para dar a tu porfía } \\
& \text { el dulce fin que verás } \\
& \text { (p. 970). }
\end{aligned}
$$

Existen, por tanto, una serie de coincidencias entre la situación del libro de caballerías y la de la comedia cervantina. No creo que podamos descartar que un libro que sin duda leyó influyera en la imaginación cervantina al narrar cómo un caballero cristiano ha de resistirse a los requerimientos amorosos de una mujer infiel en las tierras de ella, en las que el hombre se encuentra en situación de inferioridad. Aunque también aparece en otros libros de caballerías, quizá sea el episodio de Palmerín de Olivia el que más se adecua a la situación por la que pasa Fernando y otros personajes cervantinos.

Cabe pensar que Miguel de Cervantes, buen conocedor (como todos los hombres y mujeres de su época) de los libros de caballerías, tenía en mente estos ejemplos de cautiverios literarios en los que los enredos sentimentales jugaban el papel decisivo en la liberación cuando pergeñaba la historia de Aurelio y Silvia en El trato de Argel, y la de Costanza y Fernando, en Los baños, historias que a buen seguro haría recordar a sus espectadores aquellas fingidas historias de los libros de caballerías; así se mezclaría en sus mentes la realidad histórica vivida por algunos de ellos y la fascinación de ese mundo oriental imaginado que se presentaba en los textos caballerescos.

Por cierto, es de suponer que si Cervantes leyó (o releyó) el Palmerín de Olivia a su regreso de Argel no hubo de quedar indiferente ante las historias de cautivos que se narran en este libro de caballerías, un libro que quizá había leído con ante- 
rioridad a su propio cautiverio, si bien sólo tras haber conocido esa dura realidad, abrió los ojos ante lo que antes le pudo parecer inspiradora aventura. Quizá su rechazo al Palmerín de Olivia y su deseo de que se hiciera "rajas" tenga que relacionarse, más que con sus valores literarios, con la poca heroica actitud de su protagonista durante su cautiverio; recordemos que el caballero lucha contra sus correligionarios, no duda en besar el pie al Gran Turco y hace cualquier cosa -por indigna que sea- para salvar su vida, una actitud bien distinta de la que en realidad mantuvo el propio Cervantes con sus valientes intentos por recobrar la libertad (si hemos de creer los datos biográficos que se nos han transmitido). Tras este análisis, puede concluirse que estos episodios de Palmerín de Olivia sin duda tuvieron que influir -junto con otros textos y la propia experiencia- en la configuración literaria del tema del cautiverio en la obra cervantina.

Por tanto, los libros de caballerías no sólo explican y permiten comprender el Quijote, sino que su influencia se revela mucho mayor y se descubre en otras obras cervantinas, incluso en aquellas en las que la experiencia vital del autor se revela como fundamental.

José Julio Martín Romero

Universidad de Jaén 